Article

\title{
Experimental Continuous Casting of Nitinol
}

\author{
Gorazd Lojen 1(D, Aleš Stambolić ${ }^{2}$, Barbara Šetina Batič ${ }^{2}$ and Rebeka Rudolf ${ }^{1, *(\mathbb{D})}$ \\ 1 Faculty of Mechanical Engineering, University of Maribor, Smetanova ulica 17, 2000 Maribor, Slovenia; \\ gorazd.lojen@um.si \\ 2 Institute of Metals and Technology, Lepi pot 11, 1000 Ljubljana, Slovenia; ales.stambolic@imt.si (A.S.); \\ barbara.setina@imt.si (B.Š.B.) \\ * Correspondence: rebeka.rudolf@um.si; Tel.: +386-(2)-220-7865
}

Received: 10 March 2020; Accepted: 10 April 2020; Published: 14 April 2020

\begin{abstract}
Commercially available nitinol is currently manufactured using classic casting methods that produce blocks, the processing of which is difficult and time consuming. By continuous casting, wherein molten metal solidifies directly into a semi-finished product, the casting and processing of ingots can be avoided, which saves time and expense. However, no reports on continuous casting of nitinol could be found in the literature. In this work, $\Phi 12 \mathrm{~mm}$ nitinol strands were continuously cast. Using a graphite crucible, smelting of pure $\mathrm{Ni}$ and $\mathrm{Ti}$ in a medium frequency induction furnace is difficult, because it is hard to prevent a stormy reaction between $\mathrm{Ni}$ and $\mathrm{Ti}$ and to reach a homogeneous melt without a prolonged long holding time. Using a clay-graphite crucible, the stormy reaction is easily controlled, while effective stirring assures a homogeneous melt within minutes. Strands of nearly equiatomic chemical compositions were obtained with acceptable surface quality. The microstructure of strands containing over 50 at. $\% \mathrm{Ni}$, consisted of $\mathrm{Ti}_{2} \mathrm{Ni}$ and cubic $\mathrm{NiTi}$, whereas the microstructure of strands containing less than 50 at. \% $\mathrm{Ni}$ consisted of $\mathrm{TiNi}_{3}$ and cubic NiTi. This is consonant with the results of some other authors, and indicates that the eutectoid decomposition $\mathrm{NiTi} \rightarrow \mathrm{Ti}_{2} \mathrm{Ni}+\mathrm{TiNi}_{3}$ does not take place.
\end{abstract}

Keywords: nitinol; shape memory alloy; continuous casting; characterisation; microstructure

\section{Introduction}

Nitinol describes a group of nearly equiatomic alloys composed of nickel and titanium. The alloy was developed in the 1970s.

The alloy belongs to a group of materials called shape memory alloys (SMAs). SMAs exhibit unconventional correlations between strain, stress and temperature, based on crystallographically-reversible, thermoelastic martensitic transformation. The low-temperature and the high-temperature phases are, analogously to steel, named martensite and austenite. Austenite has a cubic (B2) structure [1]; martensite has a monoclinic B19' structure [1]. High cooling rates are necessary to prevent the decomposition of austenite into at-equilibrium low-temperature phases and to inforce martensitic transformation instead. However, since the martensitic transformation of SMAs is crystallographically reversible, high cooling rates are necessary only the first time. Once martensite is formed, further martensitic transformations are possible at any temperature-change rate, and upon cooling and heating.

Depending on temperature, stress state and deformation state, several different phenomena can occur, the most interesting being pseudoplastic deformation, one-way shape memory effect, two-way shape memory effect and superelasticity. In the martensitic state, apparently plastic deformation based on coalescence of martensitic variants, practically without dislocation glide, is possible-pseudoplastic deformation. Upon heating above the austenite start temperature, a pseudoplastically deformed element 
starts to recover its original shape-one-way shape memory effect. With special thermomechanical treatments called training, it can be achieved that a part made of SMA changes its shape, not only upon heating, but also upon cooling - two-way shape memory effect. In the austenitic state, SMAs are capable of unusually large elastic deformations, which is enabled by stress-triggered transformation: austenite $\rightarrow$ martensite-superelastic deformation. Upon unloading, transformation takes the reverse course and the material recovers its original shape. In different products, components are needed that are capable of sensing and responding, movement (stroke), mechanical work/force, energy absorption, vibration damping, etc. Using SMAs, many such components can be built without electronic controllers, switches, motors, gears, moving parts, bearings, lubrication, mechanical wear, etc. Consequently, the devices are simpler and use less material, and fewer different kinds of materials are needed to build certain devices; less or no energy is needed for operation; operation is more reliable; and, after the end of their life time, recycling is easier and more efficient.

Beside shape memory properties and superelasticity, nitinol exhibits good corrosion resistance, an unusual combination of high strength and high ductility, a strong tendency toward self-passivation, paramagnetic properties, high fatigue strength, low Young's modulus and excellent biocompatibility [2-4]. Such a unique combination of properties has enabled its use [5], especially for biomedical purposes, first in orthodontic treatments; and later on in cardiovascular surgery for stents, guide wires, filters, etc.; in orthopaedic surgery for various staples and rods; and in maxillofacial and reconstructive surgery [6,7]. Moreover, nitinol is used in aerospace, automotive, marine and chemical industries, and civil and structural engineering [8-12].

Nitinol manufacturing is a very complex process. Titanium has a high melting point, low fluidity (high viscosity) and a susceptibility to oxidation at high temperatures. These properties make Ti and its alloys difficult to cast. As molten nitinol is highly reactive, it is commonly produced by vacuum induction melting (VIM) or vacuum arc melting (VAR) $[7,13]$ and cast into ingots. Processing of ingots into semi-finished products involves a number of secondary processing methods and finishing techniques $[7,8,14]$, among them deformation and recrystallisation, whereby the microstructure is refined $[13,14]$. Further operations, such as machining and post-processing (e.g., heat treatments or surface treatments) are necessary to create finished components of the desired shape and properties, and to incorporate those components into tools and devices $[13,14]$. Difficult machining and poor workability due to its high strength, ductility and high work hardening are limiting its wider use [15]. Machining of nitinol is characterised by severe tool wear, high specific cutting energy and high strain hardening. Furthermore, functional properties are very sensitive to machining parameters [16].

To reduce the production time and costs, alternative processes can be an advantage. Relatively old alternatives to the classic route are casting and classic powder metallurgy (compressing powders into green products and sintering). However, the possibilities of these processes with respect to the shape of the products are quite limited. Compression of powders into green parts is possible only for relatively simple shapes, and pore-free products can not always be obtained [17]. Today, the most versatile alternative is additive manufacturing (AM), including selective laser melting, electron beam melting and wire-arc additive manufacturing. Additive manufacturing has significant advantages in the production of very complexly-shaped construction parts and prototypes, and a very small series of parts. In general, the static mechanical properties of AM metallic materials are comparable to conventionally fabricated metallic components [18]. Nearly fully dense products can be fabricated with optimum combinations of process parameters [19]. Even the high standards of the aerospace industry can be met [20]. Nevertheless, it is still a challenge to produce a flawless product with the intended characteristics [21], and the building orientation has an impact on the mechanical properties [22]. Besides, in spite of the high quality of AM parts, post-processing involving hot working, cold working [17], conventional machining [23], heat treatments and surface treatments, enhances the shape memory properties [24], corrosion resistance and biocompatibility. By appropriate surface treatments, corrosion resistance can be improved significantly [25]. 
In the production of wires, rods, tubes and thin sheets, the above-described alternative processes cannot be applied. Such products are still produced by casting, rolling and drawing (wires). If the production starts with thick ingots, numerous stages of rolling and intermediate annealing are necessary to obtain the desired semi-finished product, which is time consuming and expensive. In such a case, continuous casting can be the preferable alternative to ingot casting. By continuous casting, wherein molten metal solidifies directly into a semi-finished product of a relatively small cross-section, casting of ingots and several following processing steps can be avoided, which saves time and expense $[8,26,27]$. Solidification is much faster, and takes place under stationary conditions, which refines the microstructure and improves the homogeneity of the castings significantly. Continuously cast products usually have simply-shaped cross-sections. However, by using adequately shaped moulds, quite complex-shaped cross-sections can also be realised [28]. Nevertheless, the majority of nitinol wires, thin sheets and similar products are still produced by the conventional route, starting with the casting of ingots. Suzuki et al. [29] studied ductility and other properties of nitinol and some other Ti-based alloys at high temperatures, and suggested that titanium alloys could be produced successfully by continuous casting. However, only twin roll casting of wide bands was realised [30], while successful continuous casting of nitinol into strands has not yet been reported.

Our objective was to research the feasibility of continuous casting of a 50Ni-50Ti strand, which would have properties similar to products that are already on the market. A combination of vacuum induction melting (VIM) and vertical continuous casting (VCC) was used for this purpose. A number of experiments were performed, and the microstructures of the obtained strands have been studied by different characterisation techniques.

\section{Materials and Methods}

\subsection{The Nitinol Preparation}

The nitinol was prepared by vacuum induction melting of pure Ni and Ti immediately before casting. For economic reasons, the metals used in the first two trials were of lower purity, while high purity metals were used in the third and fourth trials; see Table 1 . The target composition was equiatomic, 50 at. $\% \mathrm{Ni}$ and 50 at. \% Ti, which corresponds to $55.08 \mathrm{wt}$. \% Ni and $44.92 \mathrm{wt}$. \% Ti. According to the most common Ni-Ti phase diagram proposed by Murray [31], at this composition, the alloy solidifies congruently into a cubic intermetallic compound NiTi at $1310^{\circ} \mathrm{C}$. The eutectoid decomposition of NiTi into $\mathrm{Ti}_{2} \mathrm{Ni}$ and $\mathrm{TiNi}_{3}$ at $630^{\circ} \mathrm{C}$ was proposed in older literature [32,33]. Later, Murray [31] considered the eutectoid reaction as uncertain, while in the newer literature, it was found to be unrealistic [34,35], or even nonexistent [1]. Anyway, rapid cooling, i.e., quenching, results in martensitic transformation of the undercooled NiTi. At the equiatomic chemical composition, the martensite start temperature should be at approximately $47-48^{\circ} \mathrm{C}$ [22]. As the difference between the martensite-start and finish temperature of nitinol alloys does not exceed $20-25^{\circ} \mathrm{C}[36,37]$, at room temperature the quenched alloy should be martensitic and capable of shape memory effect. Usually, nickel contents below 50 at. \% are selected if the goal is to exploit the shape memory effect. Less nickel results in higher transformation temperatures. If superelasticity should be exploited, the martensite-start temperature must be below the service temperature range, and usually nickel contents above 50.5 at. $\%$ are selected. However, in the case of continuous casting, it was expected that the cooling rate would be too low for the martensitic transformation.

\subsection{The Continuous Casting Device}

Experimental casting was performed with a laboratory scale vertical continuous casting (VCC) device, Technica Guss, which was connected to the $60 \mathrm{~kW}$ medium-frequency $(4 \mathrm{kHz})$ vacuum induction melting (VIM) furnace Leybold Hereaus. The withdrawal-parameters are programmable, so an almost arbitrary time-velocity curve can be realised (the limits being set by the performance of 
the motor and inertia of the moving parts). For more details, please see the supplementary file S1 "Continuous_casting_device".

According to the literature, a graphite crucible is the best choice with respect to contamination of the melt [38-40], although both $\mathrm{Ni}$ and Ti are carbide-forming elements. Namely, a protective layer of TiC forms quickly on the crucible wall [41], which decelerates further chemical reactions strongly, and prevents excessive contamination of the melt with carbon. Therefore, a graphite crucible was selected for the first trial. For the second, third and fourth trials, a clay-graphite crucible was used.

At first sight, it seems logical to combine a graphite crucible with a graphite mould. However, the conditions in the mould are different than in the crucible. While in the crucible no abrasive wear takes place, in the mould during each stroke, movement of solidified metal destroys the TiC protective layer mechanically, and exposes fresh graphite to the melt. In this way, the wear in the upper part of the mould is much faster than in the lower part, which is not in contact with the melt. The mould becomes conical and the strand eventually jams. According to our experience with Ni-based superalloys, this can happen within minutes after the start. In addition, the wear of the mould contributes to contamination of the strands with carbides. Therefore, a water-cooled copper mould was chosen for the experiments. Bearing in mind that one of the most important reasons for continuous casting of nitinol is to minimise time and effort for processing the strands into wires and similar semi-finished products, a mould was applied with a relatively small diameter $d=12 \mathrm{~mm}$. A yttria-stabilised zirconia nozzle was used in the first three trials, and an $\mathrm{Si}_{3} \mathrm{~N}_{4}$ nozzle in the fourth trial.

\subsection{Casting Parameters}

The charge was approximately $15 \mathrm{~kg}$. The induction power was $10 \mathrm{~kW}$ for the first $10 \mathrm{~min}$; for the next $10 \mathrm{~min} 20 \mathrm{~kW}$; and in the final $5 \mathrm{~min}, 30 \mathrm{~kW}$. Heating was interrupted during the exothermic reaction between $\mathrm{Ni}$ and Ti. During casting, 25-30 kW was necessary to maintain the casting temperature. Melting was carried out in a vacuum. Just before the start of casting, the chamber was filled with argon (purity 5.0).

Based on previous experience with Ni-based alloys [42], a withdrawal sequence "pull-pause" and melt overheating of about $100-150^{\circ} \mathrm{C}$ were estimated as appropriate. With respect to the melting point of equiatomic intermetallic phase NiTi [17], this means a casting temperature in the range $1410-1460{ }^{\circ} \mathrm{C}$. To minimise the risk of sticking and fracture of the strand in the mould, relatively low casting rates were selected, and the pulling sequence was programmed with the lowest possible acceleration. The applied parameter sets are summarised in Table 1.

\subsection{Examination of Strands}

A visual macroscopic examination was carried out of the surfaces. To estimate the actual chemical composition, X-ray fluorescence (XRF) chemical analysis of the strands followed, using a Thermo Scientific Niton XL3t GOLDD+ apparatus (Thermo Fisher Scientific, Waltham, MA, USA). Samples for microscopy and X-ray diffraction (XRD) were machined from the strands having a chemical composition near the target. For the optical microscopy, a Nikon Epiphot 300 optical microscope (Nikon, Tokio, Japan) was used, equipped with an Olympus DP-12 digital camera (Olympus, Boston, MA, USA). Scanning electron microscopy (SEM) was performed with a JEOL JSM 6500-F microscope (JEOL, Tokyo, Japan), equipped with an energy dispersive spectrometer (EDS) Oxford INCA X-SIGHT (Oxford Instruments, Abingdon, UK) and an electron backscattered diffraction (EBSD) detector Nordlys II (Oxford Instruments, Abingdon, UK). Data processing and analysis were performed with the Oxford INCA software (Oxford Instruments, Abingdon, UK) suite for EDS measurements and the Channel 5 suite for EBSD measurements. To verify the results of EDS and EBSD analysis, X-ray diffraction was performed with a PANalytical X'Pert XRD system with a Cu-cathode. 
Table 1. Materials and casting parameters.

\begin{tabular}{|c|c|c|c|c|c|}
\hline & & Trial (Strand) 1 & Trial (Strand) 2 & Trial (Strand) 3 & Trial (Strand) 4 \\
\hline \multirow{2}{*}{$\begin{array}{l}\text { Base metals purity/wt. } \\
\% \%\end{array}$} & $\mathrm{Ni}$ & 99.8 & 99.8 & 99.99 & 99.99 \\
\hline & $\mathrm{Ti}$ & Scrap, 99.8 & Scrap, 99.8 & 99.99 & 99.99 \\
\hline \multirow{2}{*}{$\begin{array}{c}\text { Target composition/wt. } \\
\%\end{array}$} & $\mathrm{Ni}$ & 55.08 & 55.08 & 55.08 & 55.08 \\
\hline & $\mathrm{Ti}$ & 44.92 & 44.92 & 44.92 & 44.92 \\
\hline \multirow{3}{*}{$\begin{array}{c}\text { Strands-analysed/wt. } \\
\%\end{array}$} & $\mathrm{Ni}$ & 63.2 & 56.5 & 54.6 & 54.6 \\
\hline & $\mathrm{Ti}$ & 34.4 & 43.3 & 45.4 & 45.4 \\
\hline & $\mathrm{Fe}$ & 1.53 & 0.2 & - & - \\
\hline \multicolumn{2}{|l|}{ Crucible } & Electrographite & Clay-graphite & Clay-graphite & Clay-graphite \\
\hline \multicolumn{2}{|l|}{ Nozzle } & $\mathrm{ZrO}_{2}$ & $\mathrm{ZrO}_{2}$ & $\mathrm{ZrO}_{2}$ & $\mathrm{Si}_{3} \mathrm{~N}_{4}$ \\
\hline \multicolumn{2}{|c|}{ Nozzle diameter/mm } & \multicolumn{4}{|c|}{11.1} \\
\hline \multicolumn{2}{|l|}{ Mould } & \multicolumn{4}{|c|}{ Copper, water-cooled } \\
\hline \multicolumn{2}{|c|}{ Mould diameter/mm } & \multicolumn{4}{|c|}{$12.0 \mathrm{~mm}$} \\
\hline \multicolumn{2}{|l|}{ Starter bar tip } & Steel & Steel & $\mathrm{Ti}$, grade 2 & Ti, grade 2 \\
\hline \multicolumn{2}{|c|}{ Melt temperature $/{ }^{\circ} \mathrm{C}$} & 1420 & 1420 & 1420 & 1420 \\
\hline \multicolumn{2}{|c|}{ Casting sequence } & \multicolumn{4}{|c|}{ Pull-pause } \\
\hline \multicolumn{2}{|l|}{ Stroke/mm } & \multicolumn{4}{|c|}{8} \\
\hline \multicolumn{2}{|l|}{ Pause/s } & 0.3 & 0.3 & 0.5 & 0.5 \\
\hline \multicolumn{2}{|c|}{ Productivity $/ \mathrm{mm} \cdot \mathrm{min}^{-1}$} & 630 & 630 & 422 & 422 \\
\hline
\end{tabular}

\section{Results}

\subsection{Casting, Chemical Composition, Surface Quality and Optical Microscopy of Strands}

First of all, both a visual examination and chemical analysis of the strands were carried out. The photographs of the strands are presented in Figure 1.

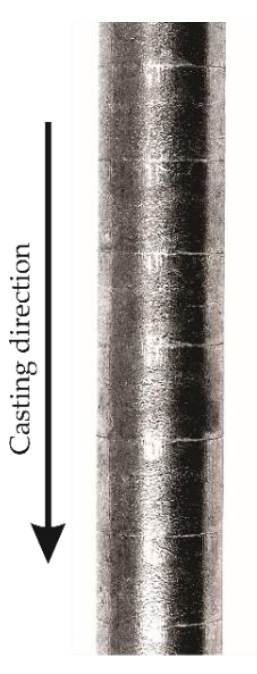

a) Strand 1

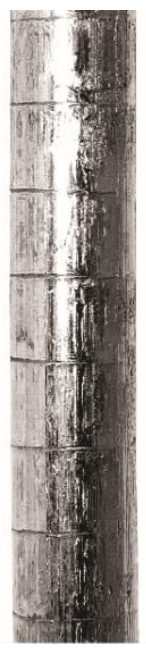

b) Strand 2

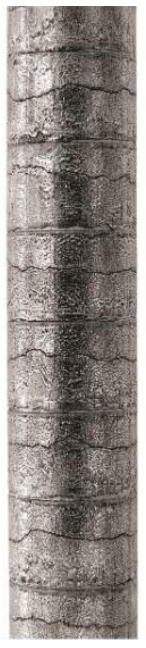

c) Strand 3

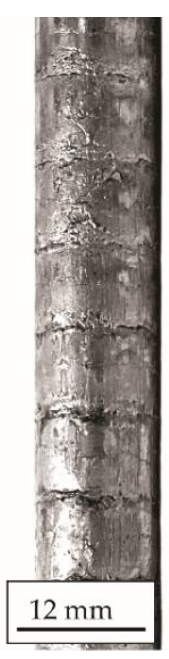

d) Strand 4

Figure 1. Macro photographs of the strands. (a) Strand 1; (b) strand 2; (c) strand 3, (d) strand 4.

The actual chemical compositions are summarised in Table 1. Because at the bottom of the crucible the melt dissolves the tip of the starter bar and the mixing in this area is the weakest, the strongest 
deviation from the target composition was expected in this area. Therefore, all samples for chemical analysis were taken from the start-end of the strands.

In trial 1, intensive sputtering during melting could not be prevented. The primary witness marks (regular circumferential grooves on the strands) were very shallow and narrow, and the surface between them was very smooth. Taking into account that witness marks are unavoidable in this casting process, the surface of the strand 1, Figure 1a, is excellent. Very shallow and narrow witness marks (regular circumferential grooves on the strands) mean that the temperature was high enough to prevent solidification deep into the nozzle. The secondary witness marks (less regular circumferential grooves, located between the primary witness marks) are hardly visible, which means that almost complete remelting of the edges of the static and dynamic skin was possible. A comprehensive explanation of the causes and mechanisms of witness mark formation can be found in the literature; e.g., [42]. However, the analysed chemical composition was far from the target composition; see Table 1 . Therefore, strand 1 was not subjected to any further examination.

The sputtering and the inadequate chemical composition in trial 1 can both be attributed to the crucible material. When producing nitinol by smelting of pure metals, the self-propagating exothermic reaction between components must be taken into account. In the case of powders, the reaction starts already in the solid state below $900{ }^{\circ} \mathrm{C}$ [43]. When smelting pellets or larger pieces of materials, the reaction starts approximately at the melting point of nickel. Depending on the furnace and the crucible material, at the latest at this point, the power should be reduced or cut-off until the reaction is completed. Otherwise, the reaction will be too stormy, which leads to overheating of the melt and intensive sputtering all over the furnace. However, in the case of a graphite crucible and a medium frequency furnace, it is very difficult to find the right moment. Namely, as also reported by other authors [44], at frequencies around $5 \mathrm{kHz}$, the magnetic field in the graphite crucible wall is substantially stronger than inside the crucible. The crucible absorbs most of the power, and heats much faster than the metallic batch in the crucible. Consequently, power must be cut-off before the reaction starts. Once it starts it is already too late, because the batch continues to absorb heat from the hot crucible.

The other disadvantage of a weak magnetic field inside the crucible is poor stirring of the melt. Due to the higher density and lower melting point of nickel compared to titanium, nickel melts first and flows to the bottom, while solid titanium remains on the top-regardless of how the crucible is charged. Even after the reaction between $\mathrm{Ni}$ and Ti and melting is completed, due to poor stirring, the Ti-concentration remains much higher on the top for a long time. Prolongation of holding time in order to improve homogeneity of the melt is not a good option, because the contamination of the melt with carbon also increases with time [41]. Therefore, the first part of strand 1 contained far too much $\mathrm{Ni}$, while the Ti-concentration was too high, closer to the surface of the melt in the crucible. Other possible reasons for inadequate composition, which, however, cannot cause such significant deviations, are: evaporation of liquid metals in the vacuum; burn-off due to residual oxygen in the protective atmosphere; errors in weighing of the batch; and the use of scrap in the first two trials, which means that the weighed mass included not only pure metals, but also some impurities, mostly oxides, the majority of which formed the slag. The extremely high Fe-concentration in the start-end of strand 1 can also be explained only with a highly inhomogeneous melt due to insufficient mixing. Namely, so much iron could not originate either from the Ti-scrap or from nickel, although Fe is a common impurity in both of them. The other source of iron was the starter bar tip. Some material from the starter bar tip always dissolves in the melt. In the case of strand 1, approximately $3 \mathrm{~mm}$ of an M8-threaded pin dissolved, which corresponds to approximately $1 \mathrm{~g}$ of steel and a concentration of $0.007 \mathrm{wt}$ \% Fe in $15 \mathrm{~kg}$ of homogeneous melt. However, to reach a concentration of over $1.5 \mathrm{wt}$ \% \% Fe, almost $230 \mathrm{~g}$ Fe would be necessary. Consequently, the only possible explanation is that stirring was too weak, and that practically all the dissolved iron remained at the bottom of the crucible.

For trial 2, a clay-graphite crucible was selected, in order to avoid problems with temperature control during smelting and insufficient stirring. Due to the poor electric conductivity of the clay-graphite, the induction power is absorbed predominantly by the metallic batch, while the crucible 
receives the major part of heat from the hot metallic batch. Thus, reduction of power resulted instantly in reduction of the heat-input into the batch, and too stormy of an exothermic reaction and sputtering of melt could have been prevented easily. The start of casting in trial 2 was smooth. The surface quality of the strand was even and quite smooth; see Figure $1 \mathrm{~b}$. However, soon after the start, the strand broke. The rupture occurred on a primary witness mark, approximately $25 \mathrm{~mm}$ below the nozzle. Examination of the strand revealed that, in the moment of rupture, the solid shell was not extremely thin (Figure 2) yet not strong enough to withstand the pulling force. This indicates that the pulling force probably increased because the strand was sticking to the mould surface due to excessive reduction of the oxide layer by the titanium-rich melt. The increasing pulling force in combination with the notch effect due to witness marks finally led to rupture.

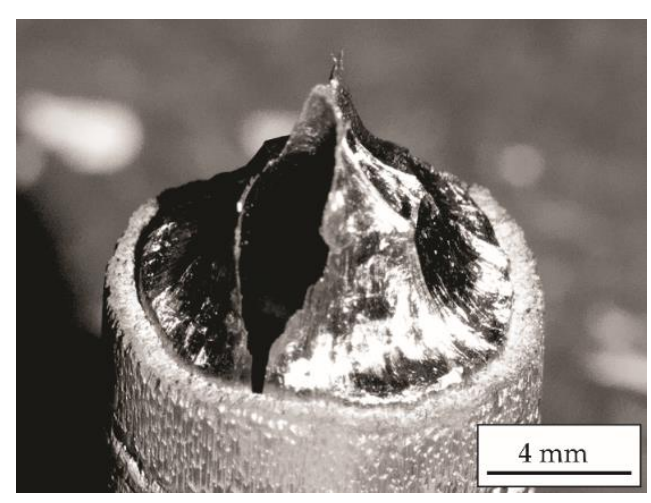

Figure 2. The fracture of strand 2.

The chemical analysis revealed that the $\mathrm{Ni}$ and Ti-contents in trial 2 were much closer to the target than in the previous trial, which means that mixing of the melt in the clay-graphite crucible was much more efficient than in the graphite crucible. Fe-content was much lower than in strand 1, but still much too high. As in trial 1, in trial 2, the iron content was too high to be caused solely by the dissolution of the starter bar tip. This indicated that the iron content in at least one of the base metals was higher than declared by the supplier. However, since the ratio Ni:Ti was not far from the target, strand 2 was used for further examination.

The longitudinal section of strand 2 was typical for continuous cast strands with a small diameter; see Figure 3.

For trial 3, as shown in Table 1, three changes were made: To improve the chemical composition, high purity primary-production metals were used, and a grade 2-titanium starter bar tip was mounted instead of a steel tip. The casting speed was reduced to decrease the temperature in the mould, an, therewith, the probability of the reaction with the melt. The start was smooth. The strand surface was a bit rougher than in the previous trials. The appearance of the longitudinal section was practically identical to the longitudinal section of strand 2-as expected, as the only difference compared to trial 2 was a longer stop between the strokes (Table 1). However, the secondary witness marks were more distinguished (Figure 1c). Such a surface is not desirable, but it may still be acceptable, as the surface layer of continuously cast strands is often removed (peeled off) prior to further processing in order to obtain a flawless surface without defects. The cause for distinguished secondary witness marks was incomplete remelting of the edges of the static and dynamic skin due to the lower average temperature in the upper part of the mould. But despite the temperature being lower, it was still too high to prevent the strand sticking to the mould completely. Figure 4 shows a copper particle sticking to the strand just below the primary witness mark. The location of the copper-particle indicates that it was torn off the mould-wall in the uppermost part of the mould, just below the ceramic nozzle, where the mould-material is exposed to the highest temperatures. 


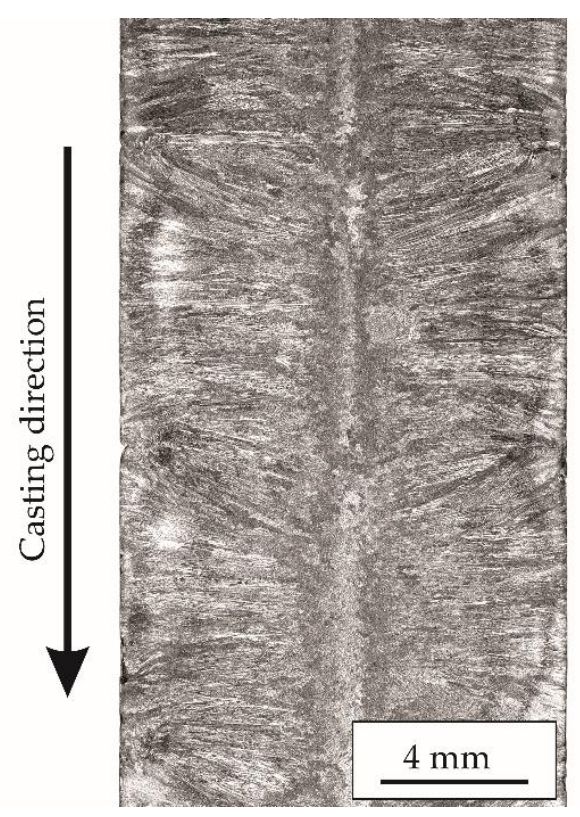

Figure 3. Longitudinal section of strand 2.

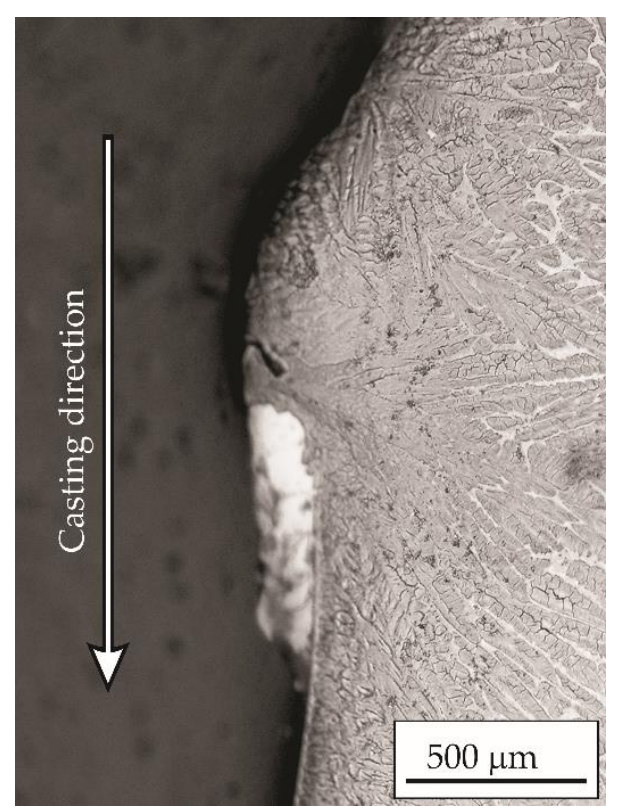

Figure 4. Copper particle below a primary witness mark on strand 3.

The temperature of the upper part of the mould should be reduced further for trial 4 . This can be achieved most effectively by decreasing either the casting speed or the temperature of the melt. However, in industrial production, high productivity is desired, while the melt temperature was, in the previous trials, only $110^{\circ} \mathrm{C}$ above the melting point. Hence, the melt-temperature and other casting parameters remained the same as in trial 3, but, instead of zirconia, the nozzle was made of silicon nitride. The thermal conductivity of silicon nitride is, at high temperatures, more than three times higher than that of zirconia [45]. This means that, in trial 4, more heat was dissipated from the melt into the cooler through the nozzle, and, consequently, the temperature of the melt entering the mould was lower. The surface of strand 4 was rough and uneven (Figure 1d). The microscopic investigation of the longitudinal sections revealed that, during the resting period, the solidification front intruded more than $1 \mathrm{~mm}$ deep into the nozzle (Figure 5a). Upon the next stroke, the solid skin moved downwards, from the nozzle into the mould, which, as usual, had a slightly larger diameter than the nozzle, and the 
melt started to flow into the gap between the mould and the solid skin which formed in the nozzle. However, it solidified before the gap was filled completely. Consequently, the primary witness marks are deep, wide and of irregular shape. In addition, as can be observed in Figure 5a, the melt in the gap could not remelt the skin which formed in the nozzle. Additionally, at the secondary witness marks, the edges of the static and dynamic skin were not remelted, and formed a bond strong enough to withstand the first stroke after their formation. Therefore, cracks formed at a large number of secondary witness marks (Figure $5 b$ ). Due to the cracks at the witness marks, the strand soon broke and the trial was interrupted.
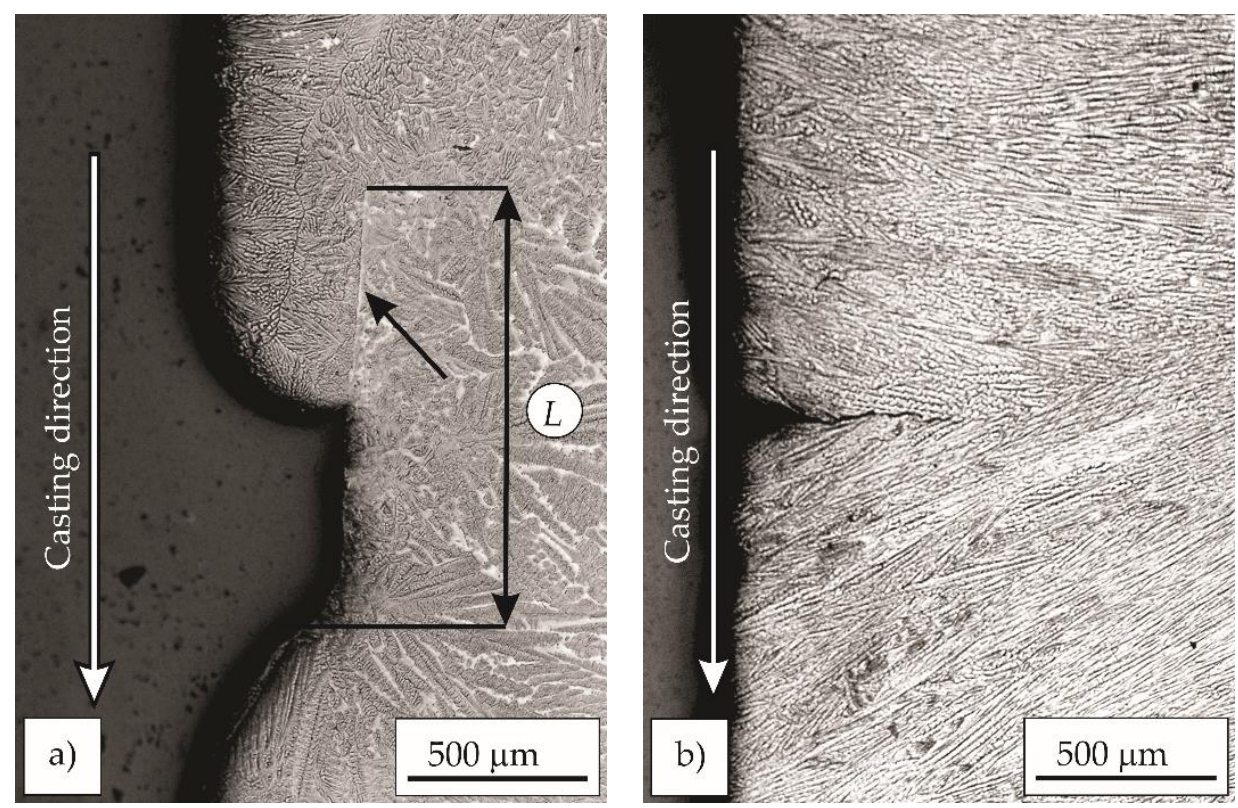

Figure 5. Strand 4: (a) Primary witness mark; the distance L marks the approximate length of the solid skin formed when the solidification front protruded into the nozzle. Upon the following stroke, this skin remained solid in spite of being covered with melt (indicated by the arrow). (b) Crack on a secondary witness mark.

For a smoother surface with shallow witness marks, the temperature in the mould must be high enough. Sufficiently high temperature assures that the solidification front cannot advance into the nozzle (consequently, no, or very shallow primary witness marks occur). It also assures complete remelting of the edges of static and dynamic skin (consequently, very shallow or almost invisible secondary witness marks occur). However, the temperature must not be too high either. It must be low enough to prevent sticking to the mould. Sticking damages the mould and shortens its service life. On the other hand, sticking increases pulling forces, and therefore, a thicker solid skin must form to withstand the pulling force at the start of the next stroke. To obtain a thicker solid skin, the cooling rate must increase. Finding the optimum combination of casting parameters and materials for the crucible, nozzle and mould to fulfil all these conditions at the same time will require further effort.

\subsection{SEM and Phase Analysis}

Strands 2 and 3 were subjected to electron microscopy and phase analysis. Strand 1 had inadequate chemical composition, and was, therefore, irrelevant. In trial 4, the alloy produced in trial 3 was reused, and therefore, apart from the worse surface, no significant differences compared to strand 3 were expected.

The microstructure of strand 2 consisted of three phases. The two-phase areas prevailed strongly, and only some small areas containing a few dark particles of a third phase were observed (Figure 6). The dark, almost black particles were identified as Ti-carbides. The EDS analysis showed approximately 
$12.6 \mathrm{wt}$. \% C, $84.6 \mathrm{wt}$. \% Ti and $2.9 \mathrm{wt} \% \mathrm{Ni}$. The ratio C:Ti corresponded very well to the $\mathrm{TiC}$, and the EBSD patterns obtained from these particles were also characteristic for cubic TiC. The grey areas were recognised as cubic NiTi, and the lightest, almost white phase, was identified as hexagonal $\mathrm{Ni}_{3} \mathrm{Ti}_{\text {. }}$

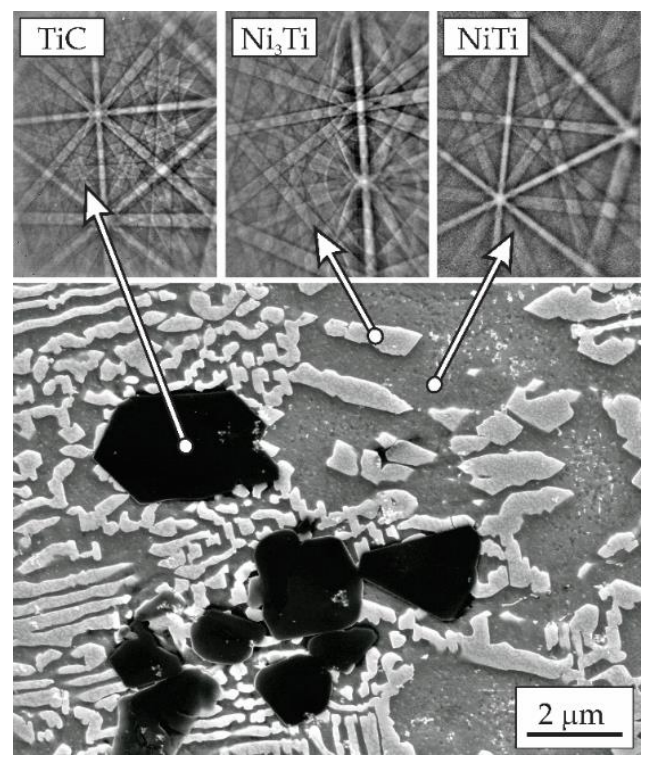

Figure 6. Microstructure of strand 2: SEM image. Three phases were observed. Strongly prevailing cubic $\mathrm{NiTi}$ (light grey), hexagonal $\mathrm{Ni}_{3} \mathrm{Ti}$ (almost white), and some small groups of TiC-particles (dark, almost black). Kikuchi patterns of these three phases, obtained by the EBSD system, are presented on the top.

The fact that no carbon was detected with XRF chemical analysis can be explained with the low concentration of carbon, below the detection limit of the method. In spite of the iron-content, no binary or ternary Fe-compounds were detected, either by XRD or by scanning electron microscopy. This can be explained with the substantial solubility of iron in $\mathrm{Ni}$-Ti compounds, especially in $\mathrm{Ni}_{3} \mathrm{Ti}_{\text {and }} \mathrm{NiTi}_{2}$ [46], in which, according to several authors [46,47], iron occupies Ni-sites predominantly.

In strand 3, only two phases were observed, Figure 7. They were identified as cubic NiTi and cubic $\mathrm{NiTi}_{2}$.

XRD analysis confirmed the presence of the phases identified by EBSD in strands 2 and 3 . The X-ray diffractograms are available in the supplementary file S2 "X-ray diffractograms".

Martensitic Ni-Ti has a monoclinic structure [1], and it was not detected in our strands. The cubic structure of the detected NiTi indicates that martensitic transformation did not take place. Consequently, if the eutectoid decomposition is possible at all, it should have taken place, and the microstructure of all our strands should contain no $\mathrm{NiTi}$, but apart from impurities, solely $\mathrm{Ti}_{2} \mathrm{Ni}$ and $\mathrm{TiNi}_{3}$. However, strand 2, containing more than $55.08 \mathrm{wt}$ \% (i.e., more than 50 at \% Ni) and some iron, consisted of cubic $\mathrm{NiTi}, \mathrm{TiNi}_{3}$ and $\mathrm{TiC}$, while strand 3, containing less than $55.08 \mathrm{wt}$. $\% \mathrm{Ni}$, consisted of cubic NiTi and $\mathrm{Ti}_{2} \mathrm{Ni}$. Taking into account the analysed chemical compositions, such microstructures are consonant with the theory that no eutectoid reaction takes place $[1,34]$. 


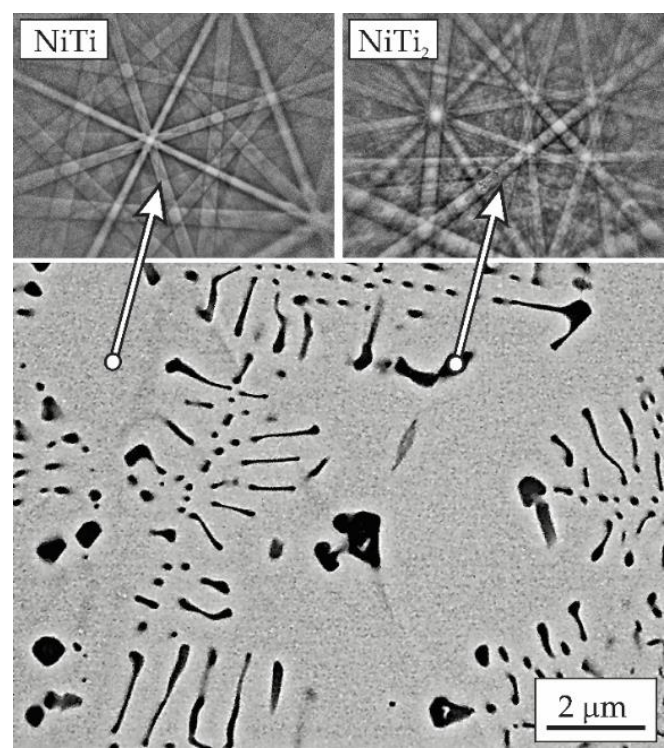

Figure 7. Microstructure of strand 3. SEM image. Two phases were observed. Strongly prevailing cubic NiTi (grey), cubic $\mathrm{NiTi}_{2}$ (dark, almost black). Kikuchi patterns of $\mathrm{NiTi}$ and $\mathrm{NiTi}_{2}$, obtained by the EBSD system, are presented on the top.

\section{Conclusions}

The following main conclusions can be drawn from this study:

(1) Smelting of pure Ni and pure Ti in a medium frequency VIM furnace using a graphite crucible is difficult. The crucible heats much faster than the metallic batch, and therefore, it is hard to prevent a stormy exothermic reaction between the $\mathrm{Ni}$ and $\mathrm{Ti}$ and excessive sputtering.

(2) Stirring of the melt in a graphite crucible in a medium frequency VIM furnace is rather inefficient. Therefore, if nitinol is produced by smelting of pure metals, the alloy is inhomogeneous.

(3) Utilisation of a clay-graphite crucible solves the problem of energy-input control efficiently during the exothermic reaction, and facilitates efficient stirring of the melt. However, the acceptability of clay-graphite with respect to melt purity remains to be confirmed by chemical analysis-methods with lower detectability limits for carbon and oxygen than used in this research.

(4) Continuous casting of nitinol strands of a relatively small diameter, $12 \mathrm{~mm}$, and acceptable surface quality directly from the melting crucible, was possible. Yet, finding the optimum combination of casting parameters and materials for the crucible, nozzle and mould, requires further effort.

(5) The microstructures of continuously cast nitinol strand 2 consisting of $\mathrm{Ti}_{2} \mathrm{Ni}$ and cubic NiTi, and strand 3 consisting of $\mathrm{TiNi}_{3}$ and cubic NiTi, support the theory that the eutectoid decomposition $\mathrm{NiTi} \rightarrow \mathrm{Ti}_{2} \mathrm{Ni}+\mathrm{TiNi}_{3}$ at $630{ }^{\circ} \mathrm{C}$ does not exist.

Supplementary Materials: Supplementary files are available online at http://www.mdpi.com/2075-4701/10/4/505/s1. Supplementary information S1: Continuous casting device. Supplementary information S2: X-ray diffractograms.

Author Contributions: This article was conceptualised by G.L., A.S. and R.R.; methodology, G.L. and R.R.; validation, G.L., A.S. and R.R.; formal analysis, B.Š.B.; investigation, G.L., A.S. and R.R.; writing一original draft preparation, G.L., A.S. and R.R.; writing-review and editing, G.L., A.S. and R.R.; supervision, R.R.; project administration, R.R.; funding acquisition, R.R. All authors have read and agreed to the published version of the manuscript.

Funding: This research was partially funded by the Slovenian Research Agency, Infrastructure Core Funding number I0-0029, Research Core Funding number P2-0120 and Applied Project L2-5486.

Acknowledgments: The authors thank Črtomir Donik for performing the XRD analyses at the Institute of Metals and Technology, Ljubljana, Slovenia. The authors also thank the companies Magneti Ljubljana d.d. Slovenia and Akrapovič d.d. Ivančna Gorica, Slovenia for supporting this study by providing nickel and titanium.

Conflicts of Interest: The authors declare no conflict of interest. 


\section{References}

1. Taburi, T. Ti-Ni shape memory alloys. In Shape Memory Materials; Otsuka, K., Wayman, C.M., Eds.; Cambridge University Press: Cambridge, UK, 1998; pp. 49, 51.

2. Frenzel, J.; Zhang, Z.; Neuking, K.; Eggeler, G. High quality vacuum induction melting of small quantities of NiTi shape memory alloys in graphite crucibles. J. Alloys Compd. 2004, 385, 214-223. [CrossRef]

3. Kwok, D.T.K.; Schulz, M.; Hu, T.; Chu, C.; Chu, P.K. Surface Treatments of Nearly Equiatomic NiTi Alloy (Nitinol) for Surgical Implants. In Biomedical Engineering, Trends in Materials Science; Laskovsky, A.N., Ed.; InTech: Rijeka, Croatia, 2011; p. 279. [CrossRef]

4. Milošev, I.; Kapun, B. The corrosion resistance of Nitinol alloy in simulated physiological solutions Part 1 : The effect of surface preparation. Mater. Sci. Eng. C 2012, 32, 1087-1096. [CrossRef]

5. Halani, R.P.; Kaya, I.; Shin, Y.C.; Karaca, H.E. Phase transformation characteristics and mechanical characterization of nitinol synthesized by laser direct deposition. Mater. Sci. Eng. A 2013, 559, 836-843. [CrossRef]

6. Duerig, T.; Pelton, A.; Stockel, D. An overview of nitinol medical applications. Mater. Sci. Eng. A 1999, 273-275, 149-160. [CrossRef]

7. Russell, S.M. Nitinol melting and fabrication. In Proceedings of the International Conference on Shape Memory and Superelastic Technologies, Pacific Groove, CA, USA, 3 April-4 May 2000; Russell, M.S., Pelton, R.A., Eds.; SMST: Freemont, CA, USA, 2001; p. 1.

8. Ashby, F.M.; Jones, R.H.D. Engineering Materials 2-An Introduction to Microstructures, Processing and Design, 2nd ed.; Elsevier Butterworth-Heinemann: Oxford, UK, 1998.

9. Simka, W.; Sadkowski, A.; Warczak, M.; Iwaniak, A.; Dercz, G.; Michalska, J.; Maciej, A. Characterization of passive films formed on titanium during anodic oxidation. Electrochim. Acta 2011, 56, 8962-8968. [CrossRef]

10. Weng, F.; Chen, C.; Yu, H. Research status of laser cladding on titanium and its alloys: A review. Mater. Des. 2014, 58, 412-425. [CrossRef]

11. Fu, C.H.; Sealy, M.P.; Guo, Y.B.; Wei, X.T. Finite element simulation and experimental validation of pulsed laser cutting of nitinol. J. Manuf. Process. 2015, 19, 81-86. [CrossRef]

12. Groover, M.P. Fundamentals of Modern Manufacturing: Materials, Processes, and Systems, 5th ed.; John Wiley \& Sons, Inc.: Hoboken, NJ, USA, 2013; p. 150.

13. Wu, H.M. Fabrication of Nitinol Materials and Components. Proceedings of the International Conference on Shape Memory and Superelastic Technologies, Kunming, China, 2001. Mater. Sci. Forum 2002, 394-395, 285-292. [CrossRef]

14. Hodgson, D.E. Fabrication, heat treatment and joining of nitinol components. In Proceedings of the International Conference on Shape Memory and Superelastic Technologies, Pacific Groove, CA, USA, 3 April-4 May 2000; Russell, M.S., Pelton, R.A., Eds.; SMST: Freemont, CA, USA, 2001; pp. 13-23.

15. Farhang, B.; Ravichander, B.B.; Venturi, F.; Amerinatanzi, A.; Moghaddam, N.S. Study on variations of microstructure and metallurgical properties in various heat affected zones of SLM fabricated Nickel-Titanium alloy. Mater. Sci. Eng. A 2020. [CrossRef]

16. Kaya, E.; Kaya, I. A review on machining of NiTi shape memory alloys: The process and post process perspective. Int. J. Adv. Manuf. Technol. 2018. [CrossRef]

17. Elahinia, M.H.; Hashemi, M.; Tabesh, M.; Bhaduri, S.B. Manufacturing and processing of NiTi implants: A review. Prog. Mater. Sci. 2012, 7, 911-946. [CrossRef]

18. Frazier, W.E. Metal Additive Manufacturing: A Review. J. Mater. Eng. Perform. 2014, 23, 1917-1928. [CrossRef]

19. Pal, S.; Lojen, G.; Kokol, V.; Drstvensek, I. Evolution of metallurgical properties of Ti-6Al-4V alloy fabricated in different energy densities in the Selective Laser Melting technique. J. Manuf. Process. 2018, 35, 538-546. [CrossRef]

20. Gisario, A.; Kazarian, M.; Martina, F.; Mehrpouya, M. Metal additive manufacturing in the commercial aviation industry: A review. J. Manuf. Syst. 2019, 53, 124-149. [CrossRef]

21. Dilip, J.J.S.; Zhang, S.; Teng, C.; Zeng, K.; Robinson, C.; Pal, D.; Stucker, B. Influence of processing parameters on the evolution of melt pool, porosity, and microstructures in Ti-6Al-4V alloy parts fabricated by selective laser melting. Prog. Addit. Manuf. 2017, 2, 157-167. [CrossRef] 
22. Pal, S.; Gubeljak, N.; Hudak, R.; Lojen, G.; Rajtukova, V.; Predan, J.; Kokol, V.; Drstvensek, I. Tensile properties of selective laser melting products affected by building orientation and energy density. Mater. Sci. Eng. A 2019, 743, 637-647. [CrossRef]

23. Pidge, P.A.; Kumar, H. Additive manufacturing: A review on 3 D printing of metals and study of residual stress, buckling load capacity of strut members. Mater. Today Proc. 2020, 21, 1689-1694. [CrossRef]

24. Khoo, Z.X.; An, J.; Chua, C.K.; Shen, Y.F.; Kuo, C.N.; Liu, Y. Effect of Heat Treatment on Repetitively Scanned SLM NiTi Shape Memory Alloy. Materials 2019, 12, 77. [CrossRef]

25. Dehghanghadikolaei, A.; Ibrahim, H.; Amerinatanzi, A.; Hashemi, M.; Moghaddam, N.S.; Elahinia, M. Improving corrosion resistance of additively manufactured nickel-titanium biomedical devices by micro-arc oxidation process. J. Mater. Sci. 2019, 54, 7333-7355. [CrossRef]

26. Beddoes, J.; Bibby, M.J. Principles of Metal Manufacturing Processes; Elsevier Butterworth-Heinemann: Oxford, UK, 2003; p. 21.

27. Pehlke, R.D. Steel continuous casting. In ASM Handbook Volume 15, Casting; Viswanathan, S., Apelian, D., Donahue, R.J., Gupta, B.D., Gywn, M., Jorstad, J.L., Monroe, R.W., Sahoo, M., Prucha, T.E., Twarog, D., Eds.; AMS Int.: Materials Park, OH, USA, 2008; pp. 918-919.

28. Black, J.T.; Kohser, R.A. Materials and Processes in Manufacturing, 10th ed.; John Wiley \& Sons, Inc.: Hoboken, NJ, USA, 2008; p. 324.

29. Suzuki, H.G.; Takakura, E.; Eylon, D. Hot strength and hot ductility of titanium alloys-A challenge for continuous casting process. Mater. Sci. Eng. A 1999, 263, 230-236. [CrossRef]

30. Goryczka, T.; Ochin, P. Characterization of a Ni50Ti50 shape memory strip produced by twin roll casting technique. J. Mater. Process. Technol. 2005, 162-163, 178-183. [CrossRef]

31. Murray, J.L. Nickel-Titanium. In Binary Alloys Phase Diagrams, 2nd ed.; Massalski, T.B., Okamoto, H., Subramanian, P.R., Kacprzak, L., Eds.; AMS Int.: Materials Park, OH, USA, 1990; p. 2875.

32. Duwez, P.; Taylor, J.L. The Structure of Intermediate Phases in Alloys of Titanium with I ron, Cobalt, and Nickel. JOM 1950, 2, 1173-1176. [CrossRef]

33. Gupta, S.P.; Makherjee, K. Diffusion Controlled Solid State Transformation in the Near-Equiatomic Ti-Ni Alloys. Mater. Sci. Eng. 1973, 11, 283-297. [CrossRef]

34. Otsuka, K.; Ren, X. Physical metallurgy of Ti-Ni-based shape memory alloys. Prog. Mater. Sci. 2005, 50, 511-678. [CrossRef]

35. Stöckel, D. Formgedächtnislegierungen. In Legierungen mit Formgedächtnis_Industrielle Nutzung des Shape-Memory-Effektes. Grundlagen, Werkstoffe, Anwendungen; Bartz, W.J., Wippler, E., Eds.; Expert Verlag: Ehningen bei Böblingen, Germany, 1988; p. 44.

36. Spini, T.S.; Valarelli, F.P.; Cançado, R.H.; Freitas KM, S.D.e.; Villarinho, D.J. Transition temperature range of thermally activated nickel-titanium archwires. J. Appl. oral Sci. 2014, 22, 109-117. [CrossRef] [PubMed]

37. Kök, M.; Dağdelen, F.; Aydoğdu, A.; Aydoğdu, Y. The change of transformation temperature on NiTi shape memory alloy by pressure and thermal ageing. J. Phys. Conf. Ser. 2016, 012011. [CrossRef]

38. Frenzel, J.; Neuking, K.; Eggeler, G. Induction Melting of NiTi Shape Memory Alloys-The Influence of the Commercial Crucible Graphite on Alloy Quality. Mat.-Wiss. Werkstofftech. 2004, 35, 352-358. [CrossRef]

39. Nayan, N.; Govind Saikrishna, C.N.; Ramaiah, K.V.; Bhaumik, S.K.; Nair, K.S.; Mittal, M.C. Vacuum induction melting of NiTi shape memory alloys in graphite crucible. Mater. Sci. Eng. A 2007, 465, 44-48. [CrossRef]

40. Fashu, S.; Lototskyya, M.; Davids, M.W.; Pickering, L.; Linkov, V.; Tai, S.; Renheng, T.; Fangming, X.; Fursikovc, P.V.; Tarasov, B.P. A review on crucibles for induction melting of titanium alloys. Mater. Des. 2020, 186, 108295. [CrossRef]

41. Zhang, Z.; Frenzel, J.; Neuking, K.; Eggeler, G. On the reaction between NiTi melts and crucible graphite during vacuum induction melting of NiTi shape memory alloys. Acta Mater. 2005, 53, 3971-3985. [CrossRef]

42. Zupanič, F.; Bončina, T.; Lojen, G.; Markoli, B.; Spaić, S. Structure of the continuously cast Ni-based superalloy GMR 235. J. Mater. Process. Technol. 2007, 186, 200-206. [CrossRef]

43. Novák, P.; Vojtìch, V.; Pecenová, Z.; Prù, F.; Pokorný, P.; Deduytsche, D.; Detavernier, C.; Bernatiková, A.; Salvetr, P.; Knaislová, A.; et al. Formation of Ni-Ti intermetallics during reactive sintering at 800-900 ${ }^{\circ} \mathrm{C}$. Mater. Technol. 2017, 51, 679-685. [CrossRef]

44. Patidar, B.; Hussain, M.M.; Sharma, A.; Tiwari, A.P. Transient numerical analysis of induction Heating of graphite crucible at different Frequency. Int. J. Electromagn. 2016, 1, 35-46.

45. Brandes, E.A.; Brook, G.B. Smithells Metals Reference Book, 7th ed.; Butterworth Heinemann: Oxford, UK, 1992. 
46. Van Loo, F.J.J.; Vrolifk, J.W.G.A.; Bastin, G.F. Phase relations and diffusion paths in the Ti-Ni-Fe system at $900{ }^{\circ}$ C. J. Less-Common Met. 1981, 77, 121-130. [CrossRef]

47. Nakata, Y.; Tadaki, T.; Shimizu, K. Composition Dependence of Atom Location of the third element in Ti-Ni-X Shape memory alloys. Mater. Trans. JIM 1991, 32, 1120-1127. [CrossRef] 